\title{
Predisposing factors and consequences of childbearing among young unmarried women in North West, South Africa
}

\author{
Akim J. Mturi' \\ School of Research and Postgraduate Studies, Faculty of Human and Social \\ Sciences, North-West University, South Africa \\ and \\ Oxford Institute of Population Ageing, University of Oxford, UK
}

\begin{abstract}
This study aims at describing the predisposing factors and consequences of pregnancy in young girls. The main research questions addressed are why young and unmarried women bear children? And what are the consequences of having a child at an early age? A qualitative study on young mothers was conducted in the North West province of South Africa. The results revealed that pregnancy for most of the participants was unintentional and happened due to ignorance. Other predisposing factors include external pressure, wrong or sporadic use of contraception and rape. Most participants had a strong negative attitude towards induced abortion. The study provides four recommendations: revisit the life orientation programme in schools and make it more efficient in delivering sexuality education; young unmarried women should be motivated to use contraception properly if they are sexually active; advocacy is needed on use of abortion services as an option; and measures should be put in place so as to improve parentdaughter communication on sexual matters.
\end{abstract}

Keywords: Teenage pregnancy; Contraception, Abortion, Sexuality education, South Africa

\section{Résumé}

Cette étude vise à décrire les facteurs prédisposant et les conséquences de la grossesse chez les jeunes filles. Les principales questions de recherche abordées sont la raison pour laquelle les jeunes femmes célibataires portent les enfants? Et

\footnotetext{
I Correspondence:

Email: akimmturi@gmail.com / Akim.Mturi@nwu.ac.za

Telephone: +27183892222 / +27183892426

Cell phone: +27794737050

Postal Address: Private Bag X2046, Mmabatho 2735, South Africa
} 
quelles sont les conséquences d'avoir un enfant à un âge précoce? Une étude qualitative sur les jeunes mères a été menée dans la province du Nord-Ouest de l'Afrique du Sud. Les résultats ont révélé que la grossesse pour la plupart des participants était involontaire et est arrivé à cause de l'ignorance. Autres facteurs prédisposant comprennent une pression externe, une mauvaise utilisation ou sporadique de la contraception et de viol. La plupart des participants avaient une forte attitude négative envers l'avortement provoqué. L'étude fournit quatre recommandations: revoir le programme d'orientation de la vie dans les écoles; les jeunes femmes célibataires devraient être motivés à utiliser la contraception correctement si elles sont sexuellement actives; le plaidoyer est nécessaire sur l'utilisation des services d'avortement comme une option; et des mesures devraient être mises en place afin d'améliorer la communication parent-fille sur les questions sexuelles.

Mots-clés: adolescent, comportement sexuel, santé de la reproduction, $\mathrm{VIH} / \mathrm{SIDA}$, intervention, évaluation, Kenya

\section{Introduction}

The formation of a family unit usually begins with marriage, followed by childbearing. In some African countries, girls marry at an early age to bear children immediately thereafter. This is the case in high fertility countries like Niger, Burkina Faso, Mali and Uganda (Ayiga and Lwanga, 20I4). However, in South Africa and many other countries, there are a lot of women who bear children before marriage (UNFPA, 20I3). For instance, Makiwane (2010) has shown that out of every 1000 live births, 52 are born by teenage mothers in South Africa. UNFPA (20/3) also reported that in 2010 alone, 36.4 million women in developing countries of age 2024 report having had a birth before age 18 . The extent and nature of the problem of teenage fertility differs from one country to another.

The focus of this article is on childbearing before attaining age 20 for unmarried women. Many young women are still enrolled in school when they conceive (Branson et al., 20l4; Manzini, 200I). Although the South African law permits learners to stay in school while pregnant and return to school after childbirth (Department of Education, 2007; Republic of South Africa, 2006), many girls drop out because they fail to cope with both responsibilities, i.e. child rearing and schooling (Manzini, 200I; Panday et al., 2009). If they choose to continue with schooling, their performance is seen to deteriorate significantly (Panday et al., 2009).

Kaufman, de Wet and Stadler (200I) listed the following reasons for unmarried girls bearing children at such a young age: ignorance of the physiology of sex especially for rural girls; curiosity; peer pressure or feeling of competition; fear of attending clinics that are unwelcoming to young contraceptive users; and sometimes forced sex. Poor family planning services for young people accompanied by fear of 
side effects and infertility have been reported by various researchers to be a cause of young unmarried women to have children (MacPhail et al., 2007; Mfono, 1998; Wood \& Jewkes, 2006). There is also an argument that gender power dynamics in sexual control favours boys and this may influence early childbearing (Bhana \& Anderson, 2013; Preston-Whyte et al., 1990; Varga, 2003). Some argue that these girls bear children as a way of seeking financial support from boyfriends, attention and love, and eventually marriage (Kaufman et al., 200I; Zwang \& Garenne, 2006). And yet there are those who feel that these girls bear children in order to access social grants (Zwang \& Garenne, 2006) - a view which has been supported by the media, but has been contested by others (Makiwane, 2010; Udjo, 2009, 2013).

Common sense indicates that nothing can be done to stop all the teenagers from having sex. So promoting abstinence of sexual intercourse to teenagers is likely to fail, but sex does not necessarily have to lead to pregnancy if adequate precautions are taken. For instance, proper use of contraception can reduce the number of pre-marital births dramatically. Some South African researchers blame lack of communication from teachers and parents with teenagers on sexual matters and contraception (MacPhail et al., 2007; Vundule et al., 200I), which results in them not knowing what to do to protect themselves from pregnancy. Given that induced abortion is legalized in South Africa, one expects those girls who conceive unintentionally to choose not to deliver their babies, but to rather seek abortions. However, some studies argue that the high value placed on children means induced abortion is not an option for many girls (Harries et al., 20l4; Harrison et al., 2000; Mkhwanazi, 2010; Varga, 2002). In fact, some researchers have argued that some girls fall pregnant intentionally to prove their fecundity (Preston-Whyte et al., 1990; Ritcher, 1996).

This study aims to provide some more evidence which will assist in a better understanding of the phenomenon of childbearing for young unmarried women. We used young women and encouraged them to voice their point of view. The specific objectives of this study are to:

I) Investigate the predisposing factors of childbearing among young unmarried women;

2) Explore their attitudes and experiences of using reproductive health services before and after falling pregnant;

3) Explore the experience of giving birth for young unmarried women; and

4) Find out the consequences of having a child at a young age.

The research questions addressed in this paper are:

I. Why young and unmarried women bear children?

2. What are the attitudes and experiences of using reproductive health services for young unmarried women?

3. What is the experience of giving birth for young unmarried women?

4. What are the consequences of having a child at a young age? 


\section{Conceptual Framework}

The conceptual framework developed for the study of childbearing among young unmarried women is presented in Figure $\mathrm{I}$. The framework has four board categories: predisposing factors of having a baby at young age; access and use of reproductive health services, childbearing, and consequences of childbearing while young and unmarried.

I. Predisposing factors of young unmarried women to have babies, are classified into six categories:

- Lack of information on the physiology of their body or physiology of sex and what happened thereafter. Some women accept the situation and some regret the decision for the rest of their lives.

- Availability of support received from family members, government, school, community and organizations including nongovernment organisations (NGOs) and (faith-based organisations (FBOs).

- External pressure refers to the pressure from family members (mother, grandmother, etc) on a young girl to have a baby; or the boyfriend who wants proof of her fecundity; or her peers who have babies and look down on those who don't have children.

- Intentional relates to the decision of a woman to willingly have a baby because she is old enough to have one.

- Contraceptive failure refers to a situation where contraceptives were used by a woman at the time of conception. There are also those who were using contraceptives wrongly or sporadically.

- Raped or coerced relates to women who conceived as a result of rape or coerced sex that resulted in conception.

2. Access and use of reproductive health services includes:

- Contraception which refers to the attitude and use of contraception before conception.

- Abortion which refers to the attitude and use of abortion services after conception. 
African Population Studies Vol. 29, No. 2, Supplement, 2015

\begin{tabular}{|c|c|c|c|c|c|}
\hline \multirow[t]{2}{*}{ Predisposing factors } & \multicolumn{3}{|c|}{ Reproductive health services } & \multirow[t]{4}{*}{ Childbearing } & \multirow{2}{*}{ Consequences } \\
\hline & Contraception & Other RH services & Abortion & & \\
\hline Lack of information & & & & & Schooling \\
\hline $\begin{array}{l}\text { Availability of support } \\
\text { e.g. family, social grants, etc }\end{array}$ & & & & & Health \\
\hline External pressure & $\downarrow$ & Conception & & Childbirth & Marriage \\
\hline e.g. peers, partners, etc. & & & & & Poverty \\
\hline Intentional & & & & & Psychological factors \\
\hline Contraceptive failure & & & & & \\
\hline Forced/Coerced & & & & & \\
\hline
\end{tabular}

Figure I: The conceptual framework for the study of childbearing among young unmarried women. (Source: author construct). 
- Other reproductive health services which refers to the attitude of service providers such as nurses, counselling services, and provision of sexuality education.

3. Childbearing which covers only the aspect of child birth.

4. Consequences of childbearing which refers to the physical consequences of childbearing experienced by young unmarried women.

- Schooling: Most of these women are still attending school when they first conceive. Many young women drop out of school completely. The performance of those who manage to continue with schooling is affected by childbearing and the rearing of their child.

- Health: Since these women are still young, their body are not mature enough for childbearing and hence they are exposed to health issues.

- Marriage prospects: The marriage market can be affected positively or negatively. If the man wants proof of fecundity, the proof of childbearing will be a positive benefit, but some men are not willing to marry women who already have children by other men.

- Economic difficulties or poverty have been linked with having a baby at a young age.

- Psychosocial factors arising as a result of childbearing at young age include stress and psychological problems.

\section{Data Source and Methods}

Data for this article were obtained as part of a larger study dealing with sex, contraceptive use, pregnancy and motherhood of young unmarried women. A qualitative study was conducted, during October and November of 2013, in all four district municipalities of the North West province, South Africa. The North West province, dominated by Setswana speakers, is one of the provinces still rooted in cultural practices. A total of 30 focus group discussions (FGDs), each with 6-12 participants, and 49 individual indepth interviews (IDIs) were used in the analysis. The sample was chosen based on geographical division of the province and type of place of residence. Generally, the intention of IDIs was to collect information on personal experiences of childbearing, whereas FGDs collected general information on perception and norms. Altogether, 325 participants aged between 15 and 30 years took part in this study. All participants had a premarital childbearing experience before age 20. Eight field assistants (FAs) were recruited for data collection purposes, two for each district. The minimum requirement for FAs was a degree in social sciences. The FAs attended a training workshop and pilot study before the fieldwork commenced.

Participants were recruited in each district through snowball sampling. A written informed consent form was used for each participant before the interview commenced. Participants were allowed to stop if they were uncomfortable with the questions or did not want to continue with the interview. Semi structured interview guides for IDls and FGDs, developed for the broad study were used. The 
instruments were developed by the principal investigators and tested during the pilot study. All interviews were conducted in Setswana, except one which was conducted in English. All interviews were recorded. The interviews were transcribed and translated to English. More transcripts $(73.4 \%)$ were from urban participants. Data were coded and analysed using Atlas.ti version 7. Narrative analysis was the method used to analyse the data (Reissman I993, 2008).

\section{Findings}

Predisposing factors of childbearing among young unmarried women

The majority of young unmarried mothers did not intend to fall pregnant with their first child. The participants who became pregnant unintentionally were requested to explain exactly what had happened. One of the main reasons given is lack of information and hence unaware that they will fall pregnant. The excerpt presented below, a typical response for many, indicates that these girls were either ignorant of the physiology of their body and/or physiology of sexual intercourse. Many participants did not have any idea on what was going on in their body. Some were not feeling well and went to hospital thinking that they have 'gall' (gallbladder) disease, instead they were told that they were pregnant. It is surprising to note that the girls are not aware of the pregnancy until they are already in advanced stages of their pregnancy.

By the way, I found out that I cannot do something about it. I was already six months pregnant. That's when I also found out that I'm pregnant-at six months. I did not show any signs on my body because I had a big body. I just saw myself as being beautiful by day. I only found out from my neighbour when she said to me that it is not right for me looking like this. So she suggested taking me to the clinic and I got to know about my condition during that time, so did my mother.

IDI20, DKK', Urban

Some girls did not know that even if they use protection all the time, the day they do not use contraception, for whatever reason, may lead to them falling pregnant. Some participants thought they were still very young to fall pregnant or thought they cannot fall pregnant because their boyfriends are young and never had any children.

Maybe it was because I was with boyfriends that did not have children, I don't know.

IDII 7, RSM, Urban

Some believed that they will not fall pregnant because they rarely had sexual intercourse. Some thought they would not fall pregnant because they had sexual intercourse before without using protection and did not fall pregnant. Some girls were waiting to show signs of pregnancy the morning after having unprotected sex, before taking morning after pills.

No, let me tell you, we slept together and didn't use protection, but I was just ok the 
following day, nothing at all and I said to myself that maybe I am not pregnant because he ejaculated on me before and I didn't fall pregnant, so I told myself that I was also not pregnant that time, I lied to myself by believing that.

$$
\text { IDII4, NMM, Rural }
$$

There are cases where girls are told by their peers that if they remain a virgin they will die. In addition to the responses showing ignorance as explained above, there is a long list of participants who reported that they never planned to fall pregnant, but their first pregnancy just happened. It seems most of them had knowledge about contraceptives.

I went on holiday in September in Gauteng, and when I came home I was missing him and I went to see him thinking that he had condoms because he always had them. I didn't have time to buy condoms that day, because I was in a rush and when I got there he didn't have them, we only realised that we didn't have them when we were busy having sex, and our feelings were high, and we couldn't stop and he said that he will withdraw when the sperms come. But I told him that it was not ok because he enjoys me more when he is about to ejaculate.

$$
\text { IDII4, NMM, Rural }
$$

Almost all of the girls, who fell pregnant unintentionally, were shocked with disbelief when they realised that they were pregnant. With the exception of a few, these girls were still in school. They were not planning to have a family soon, and they were still under care and guidance of their parents or guardians. Most of the girls settled after a while and moved on with their lives. Some participants acknowledged that they did not choose to be pregnant, but they did not mind continuing with the pregnancy. For example one respondent said $I$ accepted it, I did not like it. From the beginning I did not like it, but I had to accept that I am a mother, a parent, I have a child. (IDII5, RSM, Rural)

Another one said For me to accept it my mother discussed with me that I was not the first one who has fallen pregnant, there were many who do that. And also that my having a child would not mean that was the end for me. I would have just to stay at home for a while. She said that after having my child I would go back to school and that she would help me with the child.

IDII 7, RSM, Urban

The participants reported two types of support they received during pregnancy and after delivery. The first is the support they got from family members, especially the mother, and the other is from the government in the form of the child support grant. The support from the family is crucial to the extent that those who do not get or those who get less support struggle to raise the child and more serious consequences are experienced later in life. It all starts when the news of pregnancy is announced. The participants reported about the mixed feelings of their mothers. Some were very happy that they are going to have a grandchild and some did not 
show their emotions, i.e. they just accepted what happened. Most mothers were very angry when they received the news of pregnancy. The participants reiterated that their mother shouted and in some cases did not talk to them for an extended period of time, but after sometime they calmed down and accepted the pregnancy. Later on they were the ones that provided support in different forms. Mothers of participants provided counselling services when life was too tough, they provided moral support and more importantly they provided economic support. Most women were raising their grandchildren to allow the participants to go back to school. The participants had a lot to say about their mothers' support, as indicated in the following excerpts.

My mother, you know how women are. She was only angry for a week, but after that she told me the things I should do when one is pregnant. She just told herself that if she abandoned me who was going to be there for me.

IDII3, NMM, Rural

Yes, they didn't say anything but they helped with everything. They bought baby clothes and paid for the transport to the hospital.

FGD I 7, BOJ, Rural

The participants also pointed out the mixed feelings on how the father and other family members reacted. Some fathers were very happy, some were very angry and some did not show any signs of emotion, but most of them eventually gave support to their daughter. Those fathers who did not support them were not able to do so, i.e. because they are very poor.

I was not expecting the reaction from my dad, I thought he would be angry at me but he was happy and said he wanted the child to be a boy. He treats the child well, he loves him, and he spoils him and doesn't even want him to fall down.

FGD /9, BOJ, Urban ....but my dad (pause), I was once in an accident I think when I was still in grade I or 2, so my dad thought that I will never be able to have children, that's what my dad thought, so when he heard that I was pregnant, he said thank God, at least I will be able to get grandchildren.

FGD2, DKK, Urban

The Child Support Grant (CSG) established in 1998 by the South African government has been critical in assisting children from poor backgrounds (Mturi et al. 20I2). In 2015 the parent or guardian of a child who qualifies for CSG gets a flat rate of SA R330 (approximately US \$25) per month, a rate that is revised every year. Surprisingly, the participants of this study did not say much about provision of CSG. Although there was no direct question on CSG, it was expected that these girls who fall pregnant, most of them still in school and from poor backgrounds, will value CSG and must be their main source of income. Very few of them mentioned this service.

My aunt registered the child because I didn't know anything, and I told them that 
I don't need to be queuing for the money when I am supposed to go to school. I told them that they should register the child and they'll use the money for the child.

IDI35, RSM, Urban

The link revealed by this study between CSG and teenage pregnancies seems to be weak. The responses from the participants do not indicate that these girls were influenced to fall pregnant in any way by the provision of CSG.

Another reason for unmarried girls to have children is failure to resist pressure from people surrounding them. Three different groups of people have been identified in this study namely peers, family, and partner/boyfriend. Out of these groups, partner pressure came out very strongly from the participants. Some participants conceived because they were under enormous pressure to have a baby or risk the relationship. In fact there are those who were promised marriage if they prove their fecundity, as found out by Preston-Whyte et al. (1990) in KwaZuluNatal. Some just agreed casually to have a baby to satisfy the needs of the partner, but some were tricked. For example, their partner says that they will put on a condom, but they don't or a hole is made in the condom so that sperm can still be transferred. Here is what participants had to say about their boyfriends:

You know, when the baby's father asked me to have a baby with him I didn't refuse because he did everything for me like buy my uniform. He did everything for me, he supported me.
IDI23, DKK, Urban

I slept with my boyfriend with a condom and I ended up being pregnant. When I found out I was pregnant, I called him and asked him why I was pregnant. In fact, I didn't call him, my parents called him because my parents were asking me [name] what happened, you are pregnant? I cried and said I am not pregnant. And they said, you are crying for nothing because you came from the clinic and they said you are pregnant. What happened? So they called him. And my mother asked him, I hear [name] saying she is pregnant, I went with her to the clinic and she said she slept with you with a condom. He said that is what she thinks; she thinks I used a condom, but I didn't. My mother asked him why did you do that for? He answered; I wanted a child with her.

FGDI0, RSM, Urban

Peer pressure from their friends and colleagues or just copying what they observed also came out very clearly during the interviews as an external factor influencing many participants to become pregnant. Some participants are pressured by their parents to have a child. For instance, the parents of an 18-year-old girl were calling her names to pressure her to conceive, until she went to church to seek help to conceive and satisfy her parents (see excerpt below). However, not many participants revealed being pushed by the family members. Although the majority of parents did not pressurize their daughters to fall pregnant, those who were happy that their daughters are pregnant need to 
be scrutinized. It is possible that they might have influenced the daughters indirectly.

My parents had written me off and I had left school because of them. So the boyfriend was pushing and pushing. You see the leather school bags, I couldn't get them at home, but he was buying me such things. [group laugh] $\mathrm{He}$ pushed and pushed and we were staying under the same roof. So he moved to Dobsenville, so he wasn't around anymore. And my mother wasn't getting involved. When we were back home...I was 18 years, and they were saying you are barren...you are barren. It was tough. I was having sex but I couldn't catch [conceive]. Then I got help from church and I got pregnant.

\section{FGDI2, BOJ, Rural}

It has already been indicated that there are participants who fall pregnant intentionally because of peer pressure, partner pressure, and family pressure. This sub-section looks at other reasons that made participants decide to have a premarital birth at an early age. Although most participants decided that it was the right time to have a child, partners/boyfriends are usually implied. So sometimes there is a thin line between participant's decision and partner pressure. In some cases participants reiterated that girls fall pregnant intentionally in order to keep their partners; they believed that a child will make a man love you more. There are cases where boredom contributed to falling pregnant. This happens to girls who finish or drop out of school and find themselves at home without much to do. As alluded to by a 24- years-old, who had finished grade 12 I was sitting at home doing nothing and I thought of having a child (FGD23, NMM, Rural).

The discussion on experience and attitudes towards using contraception before the first pregnancy has revealed that use of contraception is rare for nulliparous women in this province. Some participants reported that they did not know anything about contraception, it was first introduced to them when attending antenatal clinic or after giving birth. Contraceptive methods used by the few participants who ever used contraception before they had their first child include condom, injection and the Pill. It is quite obvious that use of condoms is sporadic. Many stopped using condoms because the participant experienced a rash, it was hurting the partner, the partner refused to use it or because it reduced sexual pleasure. There was one assertion in a focus group that couples stopped using a condom because they used it for too long and were afraid that it will therefore pass to the intestines. There are cases where the condom was broken during the sexual act, but they knowingly did not bother to replace it. The participants had a lot of negative issues to talk about injectables because of high failure rate. There were specific discussions about morning after pills or emergence contraception. The overwhelming majority of the participants did not know about them and very few ever used these pills.

As indicated above, some participants reported contraceptive failure and it was dominated by failure of condom. The finding that participants fell pregnant while using the injection needs further research as it might be due to following instructions 
wrongly. There are also unfortunate reports of rape.

Attitudes and experiences of reproductive health services

South Africa is one of the few countries in sub-Saharan Africa where induced abortion is legal. The 1996 Choice on Termination of Pregnancy Act of South Africa states that a pregnancy may be terminated either upon request of a woman during the first 12 weeks of the gestation period. After the 12th week the pregnancy can still be terminated, but with a number of listed conditions. All participants were asked if they are aware of abortion services and those who fell pregnant unintentionally were asked if they thought of using these services. The main finding is that very few participants were positive about abortion. The overwhelming majority knew about abortion services, some of them struggling to differentiate between 'backstreet' abortion services and the legal services offered in health centres and hospitals. It was surprising to note that even those who fell pregnant as a result of rape or contraceptive failure did not consider abortion as an option. A lot of reasons were given by participants for not seeking abortion services after realising that they were pregnant with their first child. Obviously, judging from the responses (Mturi, 2015), ignorance plays a crucial role. It is clear that abortion is very unpopular and childbearing is very important in this society.

It is very clear that most of these pregnancies were mistimed and many young mothers were not going to deliver them if it was not for myths and misconception they have about abortion. There was a lack of information for some participants who attempted to do something about their pregnancy by drinking any stuff they can think of (for details see Mturi, 2015). Some isolated cases reported that they actually visited the service providers, but the foetus did not come out. This shows a serious need for advocacy targeting young women in as far as the termination of pregnancy act is concerned and the safety of the procedure itself. There were few participants who supported abortion, especially if there is a good reason to do it, but at this particular time they wanted a child.

Compared to other sub-Saharan African countries, South Africa is much advanced in terms of provision of health services in general and reproductive health services in particular. So there were no serious concerns about the services rendered to these young women. However, some participants complained about bad treatment from nurses. Nurses were either yelling at the girls or did not pay much attention in taking care of them. One participant reported about a cousin who went to the clinic with her friends.

She said they were yelling at them, and asked them why they wanted to use contraceptives when they are still at school and young? And they should know that the injection might make them not to have children. But they got the injection and gave them the condoms.

IDII, NMM, Rural 


\section{Experience of giving birth for young unmarried women}

Information on the experience of giving birth to the first child was collected during in-depth interviews. Participants were asked to give as much details as possible on their experiences of giving birth, beginning from the time they started to feel pain. A closer analysis of the responses does not indicate any extraordinary problems facing these girls as compared to general population of women in childbearing age in a typical South African setting. During labour, all participants were able to get transport to take them to a health facility. The majority were transported by ambulance (even in rural areas), some by private cars, and a few used mini bus taxis (combis). Almost all deliveries were done in a hospital or a Health Centre. The few that happened at home were not by choice, but only because "the baby came very fast". The mother and child were sent to a health facility immediately after delivery. Most of them were vaginal births. Only six participants indicated that they gave birth by caesarean section, which is approximately $12 \%$ of the participants. There were reports also of few complications to the mothers such as going beyond the normal gestation period, bleeding heavily, and high blood pressure. On the other side, few babies were reported to be premature or having abnormalities, but one died after a few months. As found in the general population, these complications were isolated cases.
Consequences of having a child at a young age

The majority of the participants were still in school when they fell pregnant. As stated earlier, these girls are legally allowed to stay in school until they deliver and may also return to school after delivery. So legally, only minimum disruption is expected in their school attendance for girls who fall pregnant. However, the study reveals that this is not the case. Schooling for almost every participant who was still enrolled was affected in one way or another. The main intervening factor is availability of support from the family. Having other family members such as grandmother to take care of the baby had a crucial role in determining whether the mother of the baby was able to go back to school or not and when that was going to happen. There were cases where the family took away the baby immediately after birth so that the mother could go back to school. Hence there was a minimal effect on their schooling, but these were the few fortunate ones. The majority of participants were in the other extreme of dropping out of school because there was no one to look after the baby, and for some that was not a big deal. Here are some examples of what participants had to say.

My mother fell sick just before the June exams and I was stressed ....I decided to take my baby to Pudumong where her father's family is .... In Pudumong they were never around, they travelled frequently attending churches. Yes, my children's grandmother was always away and I felt that she would carry my child everywhere she went and would not feed her properly. So I decided it was better I 
stayed at home and took care of my child myself. I left school and decided to take care of my child. It was 2009 and I was in standard nine.

IDII 7, RSM, Urban

No, I never went back to school. Before I had my child, my mother passed away. Yes while I was still pregnant. So I was thinking about who would I leave my child with, because my older sister also had a child.... So I decided that I would stay at home and raise my child. Yes I never went to school in my grade ten as my belly had already grown big, so I quit.

IDI30, RSM, Urban

Some participants dropped out of school for different reasons to child rearing. Some just could not focus on schoolwork anymore and others left due to stigma. Surprisingly there are participants who were refused back in school after delivery.

I had to drop out of school. Yes and after the pregnancy when I am at school I could no longer hear anything and I was not interested in anything. No I missed a step, I realised I was at risk and I spoke to my teacher and told her what was going on.

IDII9, DKK, Urban

\section{Discussion and recommendations}

Teenage childbearing is a problem in the North West province, South Africa. Shisana et al. (20|4) have reported that the number of teenagers who report a sexual debut before age 15 is increasing in South
Africa, and this has implications in addressing this problem. There is a need to make sure that teenagers understand clearly the issues about sex and its consequences. This study has shown that young women who took part in the study were very ignorant on sexual matters when they had their first pregnancy, and this has made them vulnerable to unintended conception. Mkwanazi (20l0) found the same in Nyanga, Western Cape province. Evidently the teenage mothers lack information about the physiology of their body, physiology of sex, prevention of pregnancies, access and reliability of abortions services (Kaufman et al., 200I). This is a good indication that the Life Orientation Programme provided in schools is not adequate to inform these youngsters about sexual and reproductive health matters. It is important to reassess this programme and also find out what else can be done to equip these girls.

Among the initiatives which need to be considered seriously, is how to increase the use of contraception. Although the Children's Act of 2005 (as amended in 2007) allows girls as young as I 2 -years-old to access reproductive healthcare services including contraception, in practice this is not the case. The study has shown cases of nurses scolding school girls who seek these services indicating that the mentality of abstinence is still in service providers' mind regardless of the new policies. A similar finding has been reported elsewhere in the country (Wood and Jewkes, 2006). This gap needs to be addressed urgently. In addition, supply factors such as accessibility, availability and affordability need to be taken care of as well. 
One of the major finding of this study is the negative attitude of young women to induced abortion. One expects that having the Termination of Pregnancy Act in place and offering those services in the Health Centres are adequate conditions to make women seek those services. This is not the case in this study. The participants had a lot of negative things to say about abortion, some of which are based on myth. Even those who conceived as a result of rape and those who definitely did not need a child at that stage of their life still did not consider abortion as an option. The stigma on induced abortion has been observed elsewhere in Africa where abortion is legal (Kumar \& Hessini, 20II). In other countries, even those where abortion is illegal, a school girl will do anything to terminate the pregnancy so that she can continue with schooling. This study shows that there is need for advocacy on abortion services. The advocacy should deal with change of mind set, benefits, safety, and all other issues that were mentioned as a huddle to these services.

Parents were very angry when they first received the news of their daughter being pregnant. However, this did not last for long as mothers in particular provided support to young women in raising their children. Other scholars have also reported that although parents may be angry and in some cases chastise or beat them for falling pregnant (Kaufman et al. 200 I; Preston-Whyte et al. 1990) they are still the main pillar of support during their daughter's pregnancy and after giving birth. Some young women are able to go back to school after delivery because of this type of support. This is a very good idea because without such support most of them will struggle a lot to raise the child. However, it is argued that parent-daughter communication on sexual matters should be improved so as to complement the life orientation programme in schools. There is a need to find a mechanism on how to assist parents to see the bigger picture by working hard to stop pregnancies as the majority also do not approve of school girls falling pregnant.

\section{Notes}

I. District municipalities of the North West province: Dr Kenneth Kaunda (DKK), Dr Ruth Segomotsi Mompati (RSM), Ngaka Modiri Molema (NMM), and Bojanala (BOJ).

2. The author of this paper has no conflict of interest to either the project where this paper is extracted or the findings reported.

\section{References}

Ayiga, N. \& Lwanga, C. 20l4. The persistence of high fertility in subSaharan Africa: A comparative study of three countries. In: Mturi, A.J. and Agyei-Mensah, S. (eds). Explaining Fertility Differences in Sub-Saharan Africa: Projecting the Demographic Future. New York: The Edwin Mellen Press.

Bhana, D. \& Anderson, B. 2013. Gender, relationship dynamics and South African girls vulnerability to sexual risk. African Journal of AIDS Research, I2(I): 25-3I. Branson, N., Hofmeyr, C. \& Lam, D. 2014. Progress through school and the determinants of school dropout in South Africa. Development Southern Africa, 3I(I): 106-I26. 
Department of Education [South Africa]. 2007. Measures for the Prevention and Management of Learner Pregnancy. Pretoria: Department of Education.

Harries, J., Stinson, K. and Orner, P. 2014. Health care providers' attitude towards termination of pregnancy: A qualitative study in South Africa. BMC Public Health, 9: 296 doi: 10. I 186/ I47|-24589-296.

Harrison, A., Montgomery, E.T. Lurie, M. \& Wilkinson, D. 2000. Barriers to implementing South Africa's Termination of Pregnancy Act in rural KwaZulu/Natal. Health Policy and Planning, 15(4): 424-431.

Kaufman, C.E., de Wet, T. \& Stadler, J. 200I. Adolescent pregnancy and parenthood in South Africa. Studies in Family Planning, 32(2): I47-160.

Kumar, A. \& Hessini, L. 20II. Abortion Stigma. Chapel Hill, USA: IPAS.

MacPhail, C., Pettifor, A,E., Pascoe, S. \& Rees, H.V. 2007. Contraception use and pregnancy among 15-24 year old South African women: a nationally representative cross-sectional survey. BMC Medicine 5: 3 I doi: I0. I |86/ | 74|70I5-5-3I.

Makiwane, M. 2010. The Child Support Grant and teenage childbearing in South Africa. Development Southern Africa, 27(2): 193-204.

Manzini, N. 200I. Sexual initiation and childbearing among adolescent girls in KwaZulu Natal. Reproductive Health Matters, 9(I7): 44-52.

Mfono, Z. 1998. Teenage contraceptive needs in urban South Africa: A case study. International Family Planning Perspectives, 24(4): 180-183.
Mkhwanazi, N. 2010. Understanding teenage pregnancy in a post-apartheid South African township. Culture, Health and Sexuality, I2(4): 347-358.

Mturi, A. J. (2015). "Why young unmarried women bear children? A case study of North West province, South Africa." Population Horizons Working Paper No 02, Oxford Institute of Population Ageing, University of Oxford.

Mturi, A.J., Sekudu, J. and Kweka, O. 2012. "Understanding the experiences and challenges of child-headed households and the role of social grants in South Africa." Journal of Social Development in Africa 27(2): 9-34.

Panday, S., Makiwane, M. Ranchod, C. \& Letsoalo, T. 2009. Teenage Pregnancy in South Africa - with specific focus on school-going learners. Pretoria: Department of Education.

Preston-Whyte, E., Zondi, M., Mavundla, G. \& Gumede, H. 1990. Teenage pregnancy, whose problem?: Realities and prospects for action in KwaZulu/Natal. Southern African Journal of Demography, 3(I): I I-20.

Republic of South Africa. 2006. The South African Schools Act No. 84 of 1996.

Reissman, C.K. 1993. Narrative Analysis. Newbury Park, California: Sage Publications, Inc.

Reissman, C.K. 2008. Narrative Methods for the Human Sciences. London: Sage Publications, Inc.

Ritcher, L.M. 1996. A survey of reproductive health issues among urban Black youth in South Africa: Final Grant Report. Pretoria: Medical Research Council.

Shisana, O., Rehle, T., Simbayi, L.C., Zuma, K., Jooste, S.,Zungu, N., Labadarios, D. 
\& Onoya, D. 20I4. South African National HIV Prevalence, Incidence and Behaviour Survey, 2012. Cape Town: HSRC Press.

Udjo, E.O. 2009. Trends in the age pattern of fertility, 1995-2005, in the context of the child support grant in South Africa. Development Southern Africa 26(2): 289-299.

Udjo, E.O. 2013. The relationship between the Child Support Grant and teenage fertility in post-Apartheid South Africa. Social policy and Society, doi: $10.1017 / \mathrm{S}|4747464| 30000390$.

United Nations. 2013. Motherhood in childhood: Facing the challenge of adolescent pregnancy. State of World Population 2013. New York: United Nations Population Fund.

Varga, C.A. 2002. Pregnancy termination among South African Adolescents. Studies in Family Planning, 33(4): 283298.
Varga, C.A. 2003. How gender roles influence sexual and reproductive health among South African adolescents. Studies in Family Planning, 34(3): 160-172.

Vundule, C., Maforah, F., Jewkes, R. \& Jordaan, E. 200I. Risk factors for teenage pregnancy among sexually active black adolescents in Cape Town. South African Medical Journal, 91: 7380.

Wood, K. \& Jewkes, R. 2006. Blood blockages and scolding nurses: Barriers to adolescent contraceptive use in South Africa. Reproductive Health Matters, I4(27): I09-II8.

Zwang, J. \& Garenne, M. 2008. Social context of premarital fertility in rural South Africa. African Journal of Reproductive Health, I2(2): 98-1 I0. 